\title{
THE CHAIRMAN'S SUMMING-UP
}

\author{
G. J. CUNNINGHAM \\ From the Royal College of Surgeons of England
}

This symposium has enabled us to view some aspects of the advances made in cellular physiology and pathology during the past 100 years. This progress has been particularly spectacular recently as a result of the development of new biochemical, biophysical, and microscopical techniques. In introducing this study we have been particularly fortunate in having a person like Sir Roy Cameron, whose researches and depth of knowledge have placed him at "the growing edge " of the subject.

Clinical pathologists will all have welcomed a study of the practical application of modern techniques as illustrated by exfoliative cytology. Familiarity with cytoplasmic and nuclear detail now enables malignancy to be diagnosed with accuracy in an increasingly higher percentage of cases. This is of great importance, for in some cases exfoliative cytology may be the only means of diagnosis for inaccessible growths. It is particularly gratifying that this method is being more extensively used in Great Britain by pathologists who, as a whole, were reluctant to employ a technique which presented many difficulties. As in all laboratory tests an adequate specimen is essential and this was often difficult to obtain as patients, though willing, were unable to co-operate. The discovery of certain aerosols which after inhalation result in the copious outpouring of bronchial secretion has done much to improve the quality of the specimen and so facilitate diagnosis.

Although at one time bacteria tended to be regarded as distinct from other cells, recent work on their nucleic acid content has done much to indicate that their nature is essentially the same. Their biochemical content has become increasingly more important in the investigation of metabolic blockage by antibiotic substances. While new antibiotics keep appearing, agents active against the smaller viruses are more elusive and the discovery of "interferon" by Isaacs and his colleagues is of the first importance. This substance, produced when certain viruses are grown in tissue culture, causes metabolic blockage of certain viruses, and it remains to be seen whether any therapeutic application will develop from this observation in vitro. This is only one of the applications of tissue culture, a technique for which we owe so much to Dr. Honor Fell. Apart from the value of observing living or growing cells, embryonic organ culture has also been developed, whereby the influences of chemical factors on growth can be assessed. It is likely that by this means light will be thrown on the mechanism of such processes as regeneration and repair. In recent years morbid anatomy and bacteriology have seemed to stand less apart following the demonstration of tissue immunity in attempts at grafting tissues to aid the repair process. Although many differences exist between antitoxic and tissue immunity the presence of transplantable cell antigens has been demonstrated in tissue homografts. Those who have worked on this subject are well aware of the complexity of such antigens, and the recent discovery of the agardiffusion plate method by Ouchterlony may do much to aid future workers in resolving antigenic complexes. The recent dramatically successfulo kidney transplant in America in one of identical twins suffering from uraemia and chronic nephritis does much to indicate the wonderful future which lies ahead if only homovital homografts can be made a practicable proposition.

The biochemical advances need no emphasis, for they are familiar to all. Mitochondria are now known to be sensitive indicators of subtle changes in intracellular environment, and may later take on forms described many years ago as degenerative changes. Future work may do much to indicate the nature of metabolic requirements in various kinds of specialized cells. Much information in the difficult field of protein chemistry has appeared and the briefest reference to it is bound to include tribute to the outstanding work of Sir Frederick Gowland Hopkins. He indeed would be most gratified at the recent outstanding discoveries by $x$-ray crystallography of the molecular structure of insulin by Sanger and of myoglobin by Kendrew. A special class of proteins, namely enzymes, have appeared in increasing numbers, and the recent histochemical techniques give promise of future discoveries of the first magnitude and importance. The concept of localizing enzymes within individual mitochondria is indeed a great step forward. It is quite possible that combined techniques employing histochemistry 
and $x$-ray microscopy may do much towards the precise location of chemical substances within the cell, thus enabling the identification of the sites of metabolic action. In the midst of these exciting concepts, it is reassuring to learn of ways in which the recognition of enzymes can be put to use in clinical practice. The finding of abnormal enzyme contents of the blood in diseases causing cellular damage and necrosis gives promise for the future of similar valuable diagnostic aids.

As knowledge accumulates at increasing speed it becomes especially important to pause from time to time and assess the worth of all the evidence. The present year, when interest in so many places seems to centre on the living cell, seems particularly appropriate for this purpose. The World Fair at Brussels devoted a section to the living cell, and at the American Medical Association meeting at San Francisco attention was attracted by means of a large plastic model approximately one million times the size of the average cell. In these times many of us feel alarmed at the ever-widening horizons of pathology and the numerous branches of the subject which threaten to become severed from the parent stem. It is therefore reassuring to see, as we have seen to-day, pathologists, cytologists, bacteriologists, and chemical pathologists joining forces and finding common ground in the study of the cell. When we speak of the cell, which is so small, we should at the same time realize that it is large enough to encompass all groups of workers in pathology. Indeed, when we speak of the cell, we are speaking of pathology as a whole. When yet another step forward towards the full understanding of the cell is made it will only be as the result of our united efforts integrated towards a common goal. 